\title{
Papers
}

\section{Managing multiple morbidity in mid-life: a qualitative study of attitudes to drug use}

Anne Townsend, Kate Hunt, Sally Wyke

\begin{abstract}
Objective To examine attitudes towards drug use among middle aged respondents with high levels of chronic morbidity.

Design Qualitative study with detailed interviews. Setting West of Scotland.

Participants 23 men and women aged about 50 years with four or more chronic illnesses.

Main outcome measure Participants' feelings about long term use of drugs to manage chronic multiple morbidity.

Results Drugs occupied a central place in the way people managed their comorbidities. Respondents expressed an aversion to taking drugs, despite acknowledging that they depended on drugs to live as "normal" a life as possible. Respondents expressed ambivalence to their drugs in various ways. Firstly, they adopted both regular and more flexible regimens and might adhere to a regular regimen in treating one condition (such as hypertension) while adopting a flexible regimen in relation to others, in response to their experience of symptoms or varying demands of their daily life. Secondly, they expressed reluctance to take drugs, but an inability to be free of them. Thirdly, drugs both facilitated performance of social roles and served as evidence of an inability to perform such roles. Conclusions Insight into the considerable tension experienced by people managing complex drug regimens to manage multiple chronic illness may help medical carers to support self care practices among patients and to optimise concordance in their use of prescribed drugs.
\end{abstract}

\section{Introduction}

About half of the drugs prescribed for patients with long term conditions are not taken as prescribed. ${ }^{1}$ This non-adherence has been described as a "serious deficit at the core of medical practice, with consequent massive personal, societal, and economic cost." Haynes et al emphasise the need for a better understanding of non-adherence and note that, "With the astonishing advances in medical therapeutics during the past two decades, one would think that studies on the nature of non-adherence ... would flourish." But few studies of users' views of drugs have been published, especially when compared with the extensive literature on lay beliefs about illness. ${ }^{3}$ Studies of patients' ideas about prescribed drugs have focused on people with specific conditions, ${ }^{4-8}$ or on samples recruited through general practice. ${ }^{39-12}$

What is missing is the perspective of people with long term multiple morbidity. This is an important omission given that such patients receive a battery of different drugs to manage their conditions, account for a substantial amount of health service use, and can present general practitioners with particular problems in the management of comorbidity. ${ }^{13}$ We address this gap by reporting on attitudes to drug use among middle aged patients with multiple chronic conditions.

\section{Participants and methods}

This research formed part of a wider study on the experience and management of illness among people with multiple morbidity, which focused specifically on why some frequently consulted primary care services whereas others did not. Our study sample comprised respondents purposively selected from the west of Scotland twenty- 07 study. ${ }^{14}{ }^{15}$ This is an ongoing longitudinal study of the social patterning of health among men and women resident in a large, socially varied (but mainly urban) area centred on Glasgow. Respondents have completed lengthy, home based interviews conducted by nurses at roughly five-yearly intervals since 1987-8. These included detailed descriptions of chronic conditions, collected with an extended version of the question on longstanding illness ${ }^{16}$ that is included annually in the British general household survey. ${ }^{17}$ Respondents were also asked about the number of surgery consultations with their general practitioner, on their own behalf, in the year before the interview.

Analysis of data collected in 1995-6 showed that, although reported morbidity and symptoms accounted for about a third of the variation in general practitioner consultations, much remained unexplained even after taking account of other factors. ${ }^{18} 19$ In order to explore this further we conducted a qualitative study with people (born in the early 1950s) who reported high morbidity (four or more chronic conditions) in the interviews in 2000-2, half of whom were "low consulters" ( $\leq 3$ consultations in previous year) and half were "high consulters" ( $\geq 7$ consultations). This study presents all respondents' attitudes to drugs; differences between high and low consulters are addressed elsewhere.
MRC Social and Public Health Sciences Unit, University of Glasgow, Glasgow G12 8RZ

Anne Townsend

PhD student

Kate Hunt senior research scientist

Scottish School for Primary Care, NHS Education for Scotland, The Lister, Edinburgh EH8 9DR

Sally Wyke director

Correspondence to: Kate Hunt kate@ msoc.mrc.gla.ac.uk

bmj.com 2003;327:837

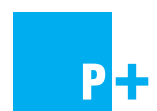

A table giving details of participants' characteristics appears on bmj.com 


\section{Data collection}

We sent letters to 41 respondents who fulfilled our morbidity and consultation criteria asking if they would be willing to take part in this additional qualitative study. We explained that this would involve two interviews, about three weeks apart, and the completion of a symptom diary for two weeks between the interviews. Twenty three people (13 women, 10 men) participated, 20 of whom took part in two interviews. AT conducted the interviews (each lasting about an hour) between October 2001 and July 2002. At the start of the interview, participants were asked to review the information sheet that had been sent with the invitation letter and to sign a consent form, which required them to confirm that they agreed to be interviewed, agreed to the interview being tape-recorded, and gave permission for extracts of their interview to be used in research publications and reports, with strict preservation of anonymity.

Of the 43 interviews, 40 took place in participants' homes. Interviews were semi-structured, but participants were encouraged to talk freely about their experiences and management strategies for their conditions. The first interview consisted of three overlapping sections-conditions and symptoms, the impact of conditions on daily life (including any action taken), and the use of formal services. The second interview allowed greater focus on management of symptoms (which had been recorded on a daily basis in a symptom diary for 15 of the respondents).

\section{Data analysis}

The recorded interviews were transcribed in full, and the analysis was based on the transcripts. We used a constant comparative method for our analysis, ${ }^{20}$ facilitated by the use of the software package nVivo. The data gathered from the interviews were wide ranging; here we focus only on how respondents spoke about their use of drugs, a major theme that emerged.

We analysed the transcripts in stages: AT checked the transcripts for accuracy against tape-recordings and made preliminary identification of themes; all authors read the transcripts separately to identify major themes; AT revised themes and the coding scheme after discussion and repeated reading of transcripts; we generated codes to label passages and applied these to transcripts; and we explored themes within and between respondents. Some themes related to drug use (such as people's aversion to drug use) were immediately obvious and were coded from an early stage of the analysis. Others (such as the higher order theme of "ambivalence") only emerged with further analysis. Once such a theme had emerged explicitly from some interviews, we re-analysed the data to establish whether others referred to the theme explicitly or implicitly and to look for deviant cases to develop and refine the findings.

\section{Results}

Participants drew on a range of resources to manage their chronic ill health. However, drugs occupied a central place in all their lives, and, as all participants had multiple chronic conditions, most drug regimens were complex and sometimes demanding and restricting. For some participants, a complex drug regimen was the only means through which they could gain equilibrium, relief from distressing symptoms, or a sense of having a "normal" life (though this varied in degree of success and setbacks) (see box 1). Although drug use seemed to have little impact on the lives of a few respondents, most accounts revealed several tensions and ambivalence in relation to drug use.

\section{"Regular" regimen $v$ "flexible" regimen}

One tension was between the use of drugs taken routinely at regular intervals in a drill-like way (as some respondents described their use of antihypertensive drugs) and a more flexible regimen that accommodated changing circumstances. Failure to keep to a set routine was often perceived to pose risks to the successful eradication, management, or containment of current symptoms or undesired future outcomes. However, almost all respondents were taking several different drugs, and they often referred to complex strategies that they had adopted so that they could remember to take the various drugs at the prescribed times. Only one respondent (with schizophrenia, depression, a peptic ulcer, diabetes, hiatus hernia, and hypertension) spoke unproblematically of his combined drug regimen (saying "keep[ing] taking the tablets" was the most important part of the management of his illnesses).

For most respondents, the experience of multiple morbidity was characterised by fluctuating symptoms, fear, uncertainty, and lack of control. In the face of uncertainties about the exact manifestation of their morbidity at a given time, the management of medication was a reflexive activity based on constant

\section{Box 1: Example of complex drug regimen to facilitate "normal" life}

"I've been trying to teach classes, and, you'll speak and at the same time think to myself, 'God, this is bloody sore,' you know, 'This is annoying.' You were wishing it was an hour later so I could take some more medicine. You were sort of, you were interfering with the sort of regime of the medicine too much, you know because if you take it earlier it's going to be earlier before you take it again. ..

"I can vary the dosage ... like during the summer holiday, I take a low dose morning, lunchtime, and a big dose at night, you know. But some days I'll maybe vary that and will maybe take slightly more in the morning when I'm not really good because I know that I'm not going to work and so on. But I still try to keep to the same daily dosage. You know, if I add something on here I try and take it off there.... But it's quite difficult, though, especially if you're trying to lead, if you're trying to be as normal as possible at the same time, you know, that's very difficult.

"So, for example, I couldn't go back to work and be like that. You know I couldn't do a job like that. And trying to come down from, say, six tablets to four tablets a day, I couldn't do that ... I cut myself right down before I went back to work because I knew that, the dosage I was on, I wouldn't be able to do the job.... I just had to get it down. So about two to three weeks before going back to work, I just got it down to three and a half tablets a day, and it was hell for six months, you know, the pain."-Respondent 16, with a pelvic abscess, asthma, eczema, and having had an ileostomy and proctolectomy 
Box 2: Example of complex drug regimen varied in response to symptoms

"My asthma's normally bad if I take a chest infection. So I up my inhalers and I up, I get put onto steroids to help that. If my colitis is bad I take the normal colitis tablets, plus I get put on steroids to stop if there is any blood or anything and Prepos [suppository] that you put inside you. So I take that as well. That's not all together. I mean, if my colitis is fine then I don't take anything, and if my asthma I just take, if its fine I just take my inhalers. I've got to take the blood pressure tablets, the ulcer tablets, and the inhalers every day, and the water tablets."--Respondent 10, with hypertension, asthma, colitis, duodenal ulcer, thyroid problems, and anxiety and depression

self assessment and monitoring. This sometimes led respondents to vary their use of drugs to gain maximum symptom control, or to seek further consultations with their general practitioner to request new drugs or higher doses of existing drugs.

"Flexible" use of painkillers was common (see box 1) and the subject of lengthy descriptions of variations in intensity of pain and drug use, although drugs for many conditions (such as colitis, emphysema, anxiety) were also described in this way (see box 2). Variations to "fixed" regimens included supplementation by increasing dose, introducing new drugs, or juggling timing. Respondents might adhere to a regular regimen in treating one condition (such as hypertension) while adopting a flexible regimen for others (see box 2), depending on their experience of symptoms in relation to the demands of their daily life. The process at its simplest was described by one respondent as "As required" (respondent 2), although this phrase masks the intricacies involved in self regulation. Descriptions of use of painkillers emphasised a struggle between wanting to take as few drugs as possible and adequate pain relief.

\section{Reluctance to take drugs $v$ the inability to be "free"} of drugs

All respondents expressed their dislike of drugs to some extent, and drug use was often portrayed as the "last resort." This description served to emphasise a degree of stoicism in their response to symptoms and typically their struggle to make "responsible" (minimal) use of drugs and (maximum) use of other management strategies (such as going to bed, avoiding certain activities) to restrict the amount of medication needed. People also spoke of not wanting to put "pills and potions" (respondent 8) into their bodies; of fears of dependency, side effects, or interactions with other drugs; and of being wary of a prescription as a substitute for a real "cure" or better strategy for managing their underlying conditions.

However, respondents also talked of their need for drugs, commonly for pain control and sometimes explicitly for "survival" (see respondent 6 in box 3, who was reluctant to take antidepressants but who expressed a different view in relation to other drugs). But respondents' accounts often focused not only on the alleviation of bodily sensations but on the desire to have a life aside from their experience of illness, to function "half normally" or to fulfil social roles or obligations (see box 3). The image used by respondent 21 in box 3, of her husband "begging" her to take pain killers and her three small daughters coming in from school to see their mother still in bed, captures some of the emotions involved in people's response to drug use. This sense, that drugs were turned to only in extremis, was commonly voiced.

\section{Drugs as facilitators of ability to perform social roles $v$ drugs as evidence of inability to perform social roles}

In some cases the main reason given for use and self regulation of drugs was to control symptoms in order to facilitate particular tasks or social roles and obligations (see examples in box 3). Undertaking activities to fulfil important social roles (as grandparents, parents, employees, etc) often aggravated distressing symptoms, but this was justified by respondents

\section{Box 3: Different presentations of "need" for drugs}

For "survival"

"I've got 13 tablets I take in the morning, I take four at lunch time and five going to bed. It's a lot of tablets to be taking in a day... . Who wants to be on medication for the rest of your life? I certainly don't, but I know I've got to because of the strokes and the high blood pressure. I have to, I know I have to, take medication; I couldn't survive without it."-Respondent 6, with asthma, hypertension, diabetes, osteoporosis, blood clots, anxiety, and depression

\section{To function "normally"}

It's [taking a range of tablets for different conditions] routine, but I tend to the ones like the dihydrocodeine. I mark down on a diary when I am taking them so that I wouldn't go over the eight in a day. Because when I am really bad, if I didn't, I've got so much pain that I can forget when I've taken it... I would love to be able to turn round and come off all these things, but to be able to function half normally I've got to take them, and if that's the way it's got to be, that's the way it's got to be."-Respondent 8 , with depression, irritable bowel syndrome, sinus problems, sciatica, ovarian cysts, migraine, and tinnitus

To fulfil tasks, social roles, or obligations

"I have to be up early in the morning to make sure I am alright for work [as a teacher]; I'll get up at six o'clock and I don't leave till eight. So I get up at six and just make sure I'm alright. I have Imodium to take ... I have to take Imodium, and that lets me get to work."-Respondent 17, with irritable bowel syndrome, migraine, hypertension, and inner ear problems

"I couldn't bear watching my three young children coming in every day and seeing me in bed. I had to do something, I knew I had to do something, and I was very loath to take these antidepressants. I only took them because I began to feel almost suicidal. At one point, my husband begged me to take them ... I couldn't bear [the children] coming in from school and seeing me still there unable to function really."-Respondent 21, with myalgic encephalitis, cyst on thyroid gland, palpitations, and allergy to dust

"Sometimes I do things I know I'm going to suffer for. But it can be a difference of, maybe, sticking a set of brake pads on my car that takes me half an hour, so maybe it'll cost me $£ 12$ to do it myself. If I'd have not done it, £60, so there’s times when I say, 'I'd better just take a couple of pain killers and do it, you know. Because they tell you you're no supposed to live like a, you know, do. At one time it was 'Lie in a bed for two, three weeks,' now they're telling you 'Just do what you want, to work as normally." -

Respondent 15 , with back pain, joint pain, photosensitivity, stomach problems, and hay fever

"I cannae, to this day, go anywhere without them [antidepressants] being in ma bag.... I cannae go the length of myself without them, but I can go without taking them. As long as I know I've got them I'm fine, but I went to the bingo one night and went into ma bag for somehin, and I thought, 'Oh God, I've nae tablets', and I widnae open the zip of ma bag ... if I had opened that and seen there were nae tablets I would've freaked, I would've really. I would've went mad. Because if I'm gaun oot, I'm gaun to the shops this afternoon, I'll say, 'I take three things with me: my purse, my Valium, and my phone.' As long as I've got them I'm happy."-Respondent 23, with breast cancer, anxiety, depression, panic attacks, and a gastric ulcer 
Box 4: Example of drug use to signify extent of ill health

Interviewer: "Can you tell me in as much detail as you can, in your own words, what conditions you have?" "I take medication for high blood pressure, which is due to a, what I was told at the [hospital] was that it's a non-specific kidney disorder. Also water tablet to help control the blood pressure as well, aspirin, and I take pain relief for my back and my leg, which I injured in work two years ago. Well, more than two years ago now. That's basically all the medication I'm on now."-Respondent 2, with disc injury, kidney problems, depression, arthritis, hypertension, and penicillin allergy

through their need to be "good" workers, parents, or partners. Drugs thus played a part both in suppressing symptoms to allow people to perform social roles central to their self identity and in alleviating symptoms aggravated by people doing more than they "should" in performing these roles. In some cases this led to a lengthy discussion of the moral dilemmas and ambiguities presented. This moral dimension to how drugs "should" be used could be reinforced by others' reactions: respondent 15 , for example, remarked that "Other people are always on to you-'Oh you're taking too many of these pain killers, blah, blah, blah'-but they've no' got the back I've got."

However, drugs could also represent ill health and act as an indicator of dysfunction (see box 4). This sometimes had the virtue of being one way of articulating to others, and affirming to oneself, the severity and progress of chronic illnesses, thus diminishing the sense of "difference" and isolation consequent on having a high burden of morbidity at a relatively young age. However, drug use could equally represent a threat to identity. Thus drugs could both be seen to restore previous identities threatened by chronic illness and to be the concrete representation of the threat to, or loss of, that identity.

\section{Discussion}

Several tensions emerged from the accounts of drug use in these chronically ill people. Drug use was central to their management of their multiple symptoms and disabilities, and self regulation to gain maximum symptom control was common. ${ }^{5}$ In common with participants in other studies, ${ }^{35-9}$ our respondents also showed an aversion to taking drugs, despite their acknowledgment that they depended on drugs to live as normal a life as possible. Respondents referred to trying not to take drugs, resourcefulness in stopping or minimising drug use, and sometimes a preference for other strategies (such as counselling) over medication. Drug use was discussed in moral terms to show how individuals remained competent though seriously challenged by their illnesses, were stoical in their response to illness, and were responsible in their roles as paid employees and family members. This raises the question why such chronically ill patients with multiple morbidity, who are much sicker and more restricted than others of their age, feel the need to justify their use of drugs in their accounts of managing their ill health.
Two factors could contribute to this. Firstly, these people are likely to need a complex array of drugs over a long period to control their chronic conditions. Rejection of short term use of drugs is not possible for them. However, research has shown a widespread cultural belief that drugs should be as little used as possible ${ }^{3-7} 9$ For example, in a sample of 544 people drawn from four general practices, $86 \%$ agreed with the statement "I would prefer not to take any medicine if I can avoid it," and 58\% agreed with "I always take as small a dose as possible." Conversely, only 24\% agreed with the statement "I would be happy to take a medicine over a long period of time," $26 \%$ agreed with "If I'm feeling ill I like to take medicine," and 15\% agreed with "When you are ill you should always take a medicine." ${ }^{12}$ Against this background, people who already may feel isolated or conspicuous because of their poor health may not wish to exaggerate this by rejecting common shared beliefs about drug taking.

Secondly, these people are relatively young to have such high levels of morbidity. They are likely to be conscious that they are more incapacitated and larger consumers of healthcare resources (in terms of drug use, general practitioners' time, etc) than their contemporaries. In their late $40 \mathrm{~s}$ and early $50 \mathrm{~s}$, they have had to come to terms with the restrictions that their chronic illnesses impose at an age when they would be expected to be at the peak of their wage earning potential with responsibility for supporting children and ageing parents. In this context it is unsurprising that they take such trouble to show that they are "really" ill and frustrated in their inability to live normal lives, to show their moral integrity in the face of

\section{What is already known on this topic}

There is widespread aversion to taking drugs and considerable non-adherence to prescribed drug regimens

Little is known about the experience of drug taking in people with chronic multiple morbidity

\section{What this study adds}

People with multiple morbidity expressed ambivalence to taking drugs in several ways: one tension was between the use of a regular drug regimen and a more flexible regimen as people self regulated their drug use in an attempt to gain equilibrium, relief from symptoms, or sense of a "normal" life

Further ambivalence was shown in people expressing reluctance to take drugs and their inability to be "free" of them; also that drugs both enabled respondents to continue to function in social roles and acted as marker for their inability to perform such roles

Drug use was discussed in moral terms to show how people remained competent though seriously challenged by their illnesses, were stoical in their response to illness, and were responsible in their roles as employees and family members 
challenges to their ideal or former identities. Their complex drug regimens mean that keeping their drug use private $^{21}$ is seldom possible, and thus it remains an intrusive and constant indicator of their poor health.

\section{Conclusions}

The failure by patients to follow prescription advice is well recognised, as are the related health and financial costs. Part of the solution to the mismatch between prescribing and consuming drugs lies in trying to understand people's experience and use of drugs. A more reciprocal relationship between doctor and patient could facilitate concordance. ${ }^{22}$ With increasing emphasis on the patient as expert, ${ }^{23}$ a genuine shared decision making process between patient and medical carers seems appropriate. This can only be achieved if the complexities and ambiguities involved in drug use for those with multiple chronic illnesses are appreciated by both parties.

We thank the people who participated in this study, Heather Boon and Jenny Donovan (the independent reviewers) for their helpful comments, and Sally Macintyre for comments on an earlier draft.

Contributors: All authors participated in the design of the study. AT conducted all the fieldwork and coding of the data. All authors contributed to data analysis and interpretation, although AT took the lead in the data analysis. All drafts of the paper were written by $\mathrm{KH}$. All authors commented critically on each draft. KH and SW are guarantors for the paper

Funding: This qualitative study was funded as a PhD studentship granted to AT by the Medical Research Council of Great Britain. The twenty-07 study, from which respondents for this qualitative study were drawn, is also funded by the MRC, and $\mathrm{KH}$ is an employee of the MRC. SW is employed by NHS Education for Scotland.

Competing interests: None declared

Ethical approval: Approval was obtained from the Glasgow University ethics committee for non clinical research involving human subjects.

1 Haynes RB, McKibbon KA, Kanani R. Systematic review of randomised trials of interventions to assist patients to follow prescriptions for medications. Lancet 1996;348:383-6.
2 Marinker M, Shaw J. Not to be taken as directed. Putting concordance for taking medicines into practice. BMJ 2003;326:348-9.

3 Britten N. Lay views of drugs and medicines: orthodox and unorthodox accounts. In: Williams SJ, Calnan M, eds. Modern medicine. Lay perspectives and experiences. London: UCL Press, 1996:48-73.

4 Conrad P. The meaning of medications: another look at compliance. Soc Sci Med 1985;20:29-37.

5 Donovan JL, Blake DR. Patient non-compliance: deviance or reasoned decision-making? Soc Sci Med 1992;34:507-13.

6 Morgan M. Perceptions and use of anti-hypertensive drugs among cultural groups. In: Williams SJ, Calnan M, eds. Modern medicine. Lay perspectives and experiences. London: UCL Press, 1996:95-116.

7 Rogers A, Day JC, Williams B, Randall F, Wood P, Healy D, et al. The meaning and management of neuroleptic medication: a study of patients with a diagnosis of schizophrenia. Soc Sci Med 1998;47:1313-23.

8 Benson J, Britten N. Patients' decisions about whether or not to take antihypertensive drugs. BMJ 2002;325:873-6.

9 Britten N. Patients' ideas about medicines: a qualitative study in a general practice population. Br J Gen Pract 1994;44:465-8.

10 Britten N, Jones R, Murphy E, Stacy R. Qualitative research methods in general practice and primary care. Fam Pract 1995;12:104-14.

11 Britten N, Stevenson F, Barry C, Barber N, Bradley C. Misunderstandings in prescribing decisions in general practice: qualitative study. $B M J$ 2000;320:484-8.

12 Britten N, Ukoumunne OC, Boulton MG. Patients' attitudes to medicines and expectations for prescriptions. Health Expect 2002;5:256-69.

13 Starfield B. New paradigms for quality in primary care. $\mathrm{Br} J$ Gen Pract 2001:51:303-9.

14 Macintyre S, Annandale E, Ecob R, Ford G, Hunt K, Jamieson B, et al. The West of Scotland twenty-07 study: health in the community. In: Martin CJ, McQueen DV, eds. Readings for a new public health. Edinburgh: Edinburgh University Press, 1989:56-74.

15 Ford G, Ecob R, Hunt K, Macintyre S, West P. Patterns of class inequality in health through the lifespan: class gradients at 15, 35 and 55 years in the West of Scotland. Soc Sci Med 1994:39:1037-50.

16 Macintyre S, Ford G, Hunt K. Do women 'over-report' morbidity? Men's and women's responses to structured prompting on a standard question about chronic illness. Soc Sci Med 1999;48:89-98.

17 Office for National Statistics. Living in Britain. Results from the 1998 general household survey. London: Government Statistical Group, 2000.

18 Hunt K, Wyke S, Walker J. Beyond the burden on illness? What factors predict general practitioner consultations? [abstract].J Epidemiol Community Health 2000;54:786.

19 Wyke S, Hunt K, Walker J, Wilson P. Frequent attendance, socio-economic status and burden or health. An investigation in the West of Scotland. Eur $J$ Gen Pract 2003;9:48-55.

20 Strauss A, Corbin J. Basics of qualitative research:techniques and procedures for developing grounded theory. London: Sage, 1998.

21 Van der Geest S, Whyte SR. The charm of medicines: metaphors and metonyms. Med Anthropol Q 1989;3:345-67.

22 Royal Pharmaceutical Society of Great Britain. From compliance to concordance. Achieving shared goals in medicine taking. London: RPSGB, 1997.

23 Department of Health. The expert patient: a new approach to chronic disease management for the 21st century. London: $\mathrm{DoH}, 2001$.

(Accepted 1 September 2003)

\section{Commentary: Does a prescribed treatment match a patient's priorities?}

Nicky Britten

Within the past 10 years several studies carried out in different settings have investigated patients' perceptions of prescribed drugs. Most of these studies have been qualitative and relatively small scale. They have all revealed considerable ambivalence about drug taking. This study by Townsend and colleagues confirms the validity of these findings for a community based sample of middle aged people in Scotland with multiple morbidities and provides a rich description of the different aspects of this ambivalence. Most prescribed drugs are taken by elderly people with chronic conditions.

This study also helps to explain quantitative research that has identified core beliefs about the perceived necessity of taking prescribed drugs as well as concerns about potential harms. ${ }^{1}$ It shows the futility of labelling patients as "compliers" or "non-compliers," as the same person may take one drug regularly while altering the dose or frequency of another. The paper shows the ambiguous yet powerful impact of drug taking on people's identity and the efforts that people make to fulfil their family and social obligations. Above all, the paper reveals the centrality of the notion of self regulation of prescribed drugs, in which patients organise their drug taking around their own priorities.

Patients' priorities may therefore be very different from prescribers' priorities, or indeed from the priorities that prescribers assume their patients to have. This paper shows clearly that patients' moral concerns and the demands of their social roles are often more important for them than the alleviation of symptoms or the cure of disease. For people struggling to retain their social identity, the issue of compliance may not be high on their agenda. Clinicians who are trying to give their patients the best evidence about treatment options and
Institute of Clinical Education, Peninsula Medical School, Universities of Exeter and Plymouth, St Luke's Campus, Exeter EX1 2LU Nicky Britten professor nicky.britten@ pms.ac.uk 
to present balanced information about risks and benefits may find it difficult to take this on board.

Clinicians need to engage with patients' priorities in order to understand how prescribed drugs will actually be used once patients have left the consulting room. Researchers developing interventions to improve adherence to treatment may not always engage with patients' priorities, ${ }^{2}$ but clinicians have immediate access to patients' perspectives. The integration, within the consultation, of best evidence and the patients' priorities is at the heart of concordance. ${ }^{3}$

Prescribed drugs may be only one element of an individual's strategy of self care. This paper shows that patients used a range of resources in managing their chronic ill health. They used a minimum-maximum strategy-minimal use of drugs and maximal use of other ways of managing their illnesses. The question for prescribers is not "How can this person use this drug most effectively?" but "How does this drug contribute to this person's self management and the attainment of his or her goals?"

1 Horne R, Weinman J, Hankins M. The beliefs about medicines questionnaire: the development and evaluation of a new method for assessing the cognitive representation. Psychol Health 1999;14:1-24.

2 Haynes RB, Montague P, Oliver T, McKibbon KA, Brouwers MC, Kanani $\mathrm{R}$. Interventions for helping patients to follow prescriptions for medications. Cochrane Database Syst Rev 2000;(2):CD000011.

3 Britten N. Concordance and compliance. In: Jones R, Britten N, Culpepper L, Gass D, Grol R, Mant D, et al, eds. Oxford textbook of primary medical care. Oxford: Oxford University Press (in press). 